\title{
Professor Masao Kawai, a pioneer and leading scholar in primatology and writer of animal stories for children
}

\author{
Masayuki Nakamichi ${ }^{1}$ (D)
}

Received: 20 July 2021 / Accepted: 28 July 2021 / Published online: 24 August 2021

(C) Japan Monkey Centre 2021

This Editorial is dedicated to Professor Masao Kawai (Fig. 1), who passed away on May 14th, 2021. He served as the sixth Editor-in-Chief of Primates for 15 years (1981-1995). The following is a collection of memories from 20 scholars.

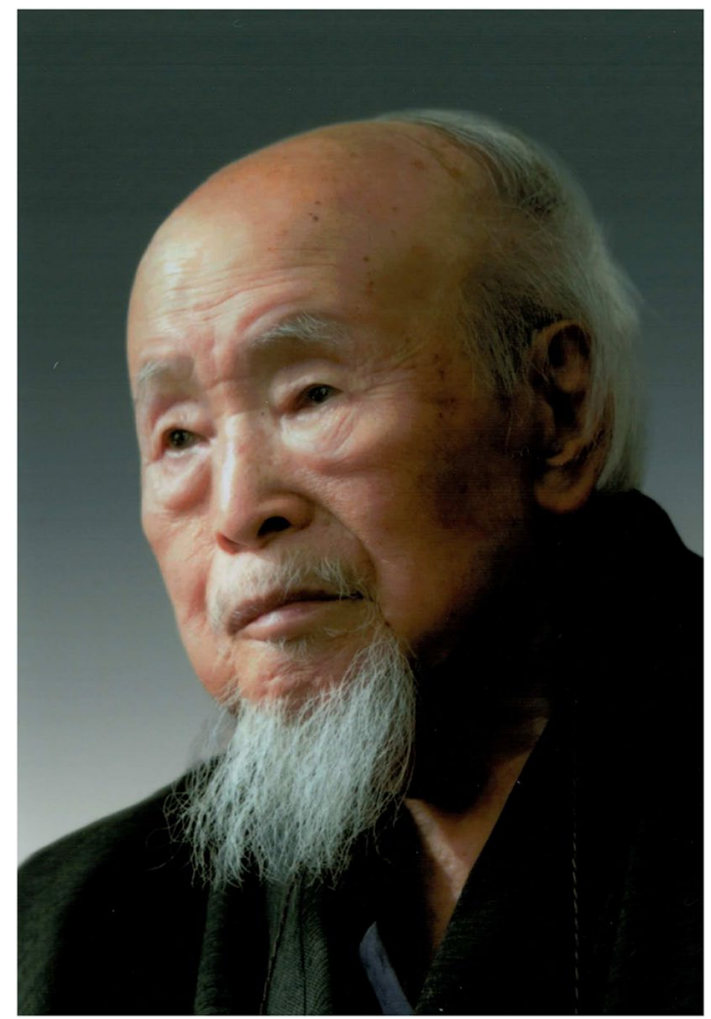

Fig. 1 Professor Masao Kawai, a pioneer and leading scholar in primatology (photo taken in January 2020; Courtesy of Ryoko Kawai)

M. Nakamichi: Editor-in-Chief, Primates

Masayuki Nakamichi

naka@hus.osaka-u.ac.jp

1 Osaka University, Suita, Japan

\section{A last eulogy for Prof. Kawai by his last student}

\section{Naofumi Nakagawa}

Professor Emeritus Masao Kawai is one of the so-called first generation of Japanese primatologists, comprising students of Kinji Imanishi, the pioneer of the discipline of Japanese primatology (Matsuzawa and Yamagiwa 2018), and the first president of the Primate Society of Japan (Kawai 1985). It is my honor and privilege to deliver this memorial address for Prof. Kawai as one of his last students.

Prof. Kawai served as my mentor until his retirement from the Primate Research Institute of Kyoto University (KUPRI), when I was in the first year of my doctoral study. Although I am now 61, when I first met him, I quickly realized that I was no match for his extensive knowledge and enlightened spirit, which led to a wide range of human networks.

Prof. Kawai was so busy that it was very difficult for me to see him; however, whenever I happened to see him in a meeting room during lunchtime, or to meet with him in his own office, he would talk to me in a friendly manner with much humor, while providing profound insights. Specifically, I cannot forget him talking in his office about the importance of comparative studies. There is no doubt that this conversation led me to make intraspecies comparisons of Japanese macaques (Macaca fuscata) (Nakagawa 1998, 2010; Nakagawa et al. 1996, 2015) and patas monkeys (Erythrocebus patas) (Nakagawa 2008), as well as interspecies comparisons between patas and tantalus monkeys (Chlorocebus tantalus) (Nakagawa 1999, 2000a, b, 2003).

I would like to mention two examples of how I followed up on his studies. The first concerns the description of cultural behaviors, such as sweet-potato washing and wheat washing, among Japanese macaques on Koshima Islet (Kawai 1965), which is his greatest and best-known 
achievement (de Waal 2003). Following Syunzo Kawamura, another member of the first generation, who briefly reported sweet-potato washing as a cultural behavior of Japanese macaques (Kawamura 1959), Kawai (1965) provided strong evidence for social learning by the macaques. Social learning is an indispensable element of cultural behavior, and Prof. Kawai reported the process of acquisition and propagation among macaques on the basis of knowledge of lineage through the maternal line. In the earliest period from 1953 to 1958 , the order of acquisition was shown to be from the young to the old, in other words, from offspring to their mother and younger to older siblings. Subsequently, however, propagation from mother to offspring was seen to occur. In contrast to Prof. Kawai's findings concerning cultural behavior, which he published at the beginning of his research career, I published my work about inter-population differences in social embracing behavior in the final stages of my research career, as the first evidence for cultural behaviors among non-provisioned Japanese macaques and the first evidence for social customs in Old World monkeys (Nakagawa et al. 2015).

The second example relates to the analogous view of human evolution based on studies of monkeys, rather than apes, which are more closely related to humans in terms of phylogeny. Prof. Kawai and his colleagues found that geladas (Theropithecus gelada) form multilevel societies, called "herds" and later renamed "bands" by Kawai et al. (1983). These bands consist of several single-male units along with all-male groups, an organization considered to be analogous to regional communities composed of several human families (Kawai 1979a). Nakagawa (2015) developed an idea proposed by Isbell et al. (1998) and discussed the benefit of the long limbs that evolved in genus Homo on the basis of my findings and on observations of patas monkeys (Nakagawa 1999, 2000a, 2003). The first fieldwork on patas monkeys was, in fact, done by a member of the KUPRI team in Cameroon directed by Prof. Kawai (Nakagawa 1989).

The seeds that Prof. Kawai sowed in the primatological field have not only germinated within me but have also blossomed across the world (e.g., Whiten et al. 1999 for culture; Grueter et al. 2012 for multilevel society). May his soul rest in peace knowing this.

\section{A tribute to Professor Masao Kawai}

\section{Pamela J. Asquith}

Masao Kawai changed the course of my life before I ever met him. In the late 1970s, I was in the final stages of completing my DPhil on anthropomorphism and comparative Western and Japanese approaches to primatology. Professor Kawai sent a courtesy copy of his book, Nihonzaru no
Seitai (Ecology of Japanese Monkeys, 1969), to my supervisor, Professor Vernon Reynolds, in Oxford. Our department rarely, if ever, received books in Japanese, and all gathered round to admire the beautiful colour plates and photographs in the volume. Of course, I was eager to know the contents of something in the original Japanese that I had been trying to glean from English abstracts of Japanese language papers as well as from what Japanese had published in English to that date. A Japanese student, who was taking a diploma course that year in our department, kindly agreed to my plea to translate the list of contents of the chapters.

There it was-a section on the kyōkan (empathetic) method which, to me at that time, was the long-sought evidence of a kind of relationship to the animals that wasn't engaged in by most Western primatologists. I made more of it as a feature of Japanese primatology at the time than it likely warranted, given that there were so many other important features of their research that led to insights on primates recognized only much later. However, Professor Kawai did mention 40 years after that publication in a 2010 interview that he "understood the monkeys' feelings."

As a postdoc embarking on next steps, my choice was inevitable: how much more I could learn as a participant observer of Japanese scientists in Japan! Professor Vernon Reynolds knew Professor Yukimaru Sugiyama, who was at the Primate Research Institute (PRI), to whom we wrote about the possibility. Professor Kawai happened to be the Director at that time and gave permission for me to conduct research there.

My journal entry for Dec 17, 1981, when I first actually met Professor Kawai, noted that my first impressions were how very welcoming, and even paternal, he was. That evening Professors Kawai, Sugiyama and I enjoyed a memorable sashimi dinner, with Professor Sugiyama translating much of our conversation for us. A mark of Professor Kawai's fortitude was that he said he had written Nihonzaru no Seitai in part while in hospital recovering from effects of TB (he first had TB in elementary school). He had lost a lung, and said he had thought he was going to die.

I did not have many encounters with Professor Kawai in research seminars or day-to-day meetings. In the early 1980s he was a very busy administrator both as Director of the PRI and Editor-in-Chief of Primates, as well as overseeing field research projects from his home base, and continuing to write. Yet he made the time to quietly ensure that I felt comfortable and welcome. He kindly invited me to some family dinners at his home on Sunday evenings, where his love of Africa was very evident. He related how one of his daughters, Rika, was named for Africa. He also gave me two of his charming books on nature written for children under his pen name, Mato Kusayama, to help me learn Japanese. His last years were spent in his beautiful hometown of Sasayama, which was the setting of many of the adventures related in the books. 
There are excellent archival materials on Professor Kawai's life and research recorded in the Kyoto University Museum Digital Archive as well as recent retrospective interviews with him that provide a deeper impression of the person. For me, through the notes and fieldwork diaries of his mentor, Kinji Imanishi, I got a sense of how meager were supplies from food to pencils and field notebooks in postwar Japan, and the perseverance required to collect their pioneering data, first on horses at Toimisaki, then on Japanese macaques. (Professor Kawai had in fact first learned individual identification methods by studies of rabbits.)

Some scientific ideas become of such fundamental importance that they are like the air we breathe, taken for granted perhaps and yet suffusing everything and on which so much of our activity depends. I would place Professor Masao Kawai's careful analyses of rank, protoculture in monkeys, levels of groupings among gelada baboons in the Simien Highlands of Ethiopia, and the comparative social and ecological study of forest- and ground-dwelling primates with the use of radio telemetry in Uganda as among those contributions. We have become so familiar with these concepts, which are so basic to our understanding of primate society, that we may lose sight of what a revelation they were, and how they opened the social universe of other primates to us. They are surely on a par with the insights of great pioneers of animal behavior research worldwide.

\section{What I learned from Professor Kawai}

\section{Frans B. M. de Waal}

As a student, I was well aware of the studies by Professor Masao Kawai. I had carefully read the 1965 collection of translations of early Japanese articles on primate behavior edited by Imanishi and Altmann (1965). In the early 1970s, while I conducted graduate research on long-tailed macaques (Macaca fascicularis), these publications greatly helped me understand macaque society. What was most remarkable in those days is that Japanese primatology recognized individual monkeys and followed their development over time. Nowadays, we take this practice for granted, but it was revolutionary at the time, controversial even. Western scientists first of all didn't believe that it was possible for people to recognize individual monkeys because they all looked alike to them. Moreover, they thought that giving monkeys names or numbers humanized them too much. They were opposed to such a practice, and mocked the Japanese approach.

Professor Kawai could of course never have made his discoveries about dependent rank if he had not recognized mothers and offspring, because the crux of the phenomenon is that maternal presence affects interactions among youngsters. In my own observations, this was abundantly

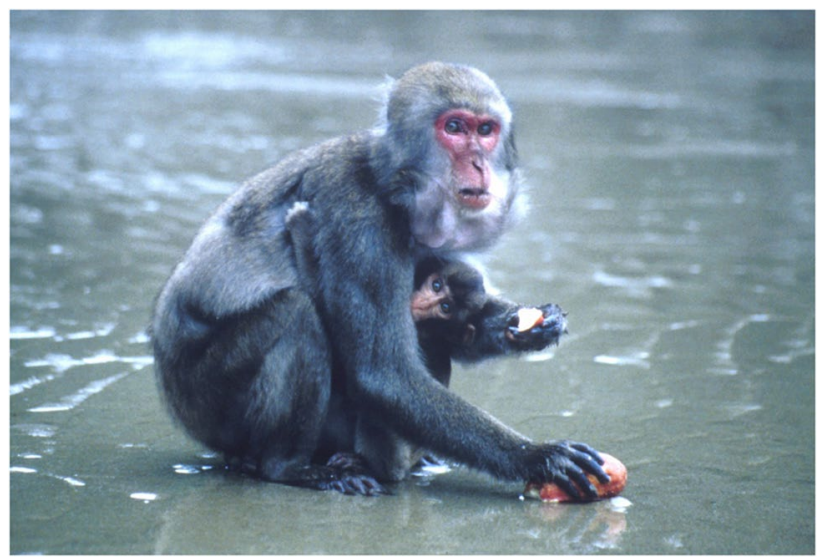

Fig. 2 A Japanese macaque mother with her infant washes a sweet potato, Koshima Island (photo by Frans B. M. de Waal)

clear, and I have admired Japanese primatology ever since. It introduced methods that we now all follow (de Waal 2003). Professor Kawai's discoveries of cultural transmission were equally seminal but engaged me only much later, leading me to visit Koshima Island twice to see the potato-washing monkeys for myself (Fig. 2). These discoveries, too, took a long time to receive wider recognition. Clearly, Professor Kawai was one of the great pioneers of primatology, well ahead of his time.

\section{Professor Masao Kawai, a memory}

\section{Robin Dunbar}

Shortly after he became Director of the Primate Research Institute, Professor Kawai very kindly invited me to spend some months at the Institute in order to collaborate with his team (Hideyuki Ohsawa and Umeyo Mori, plus Toshitaka Iwamoto at Miyazaki University) on our common research interests in the Ethiopian gelada baboons (Fig. 3). In the

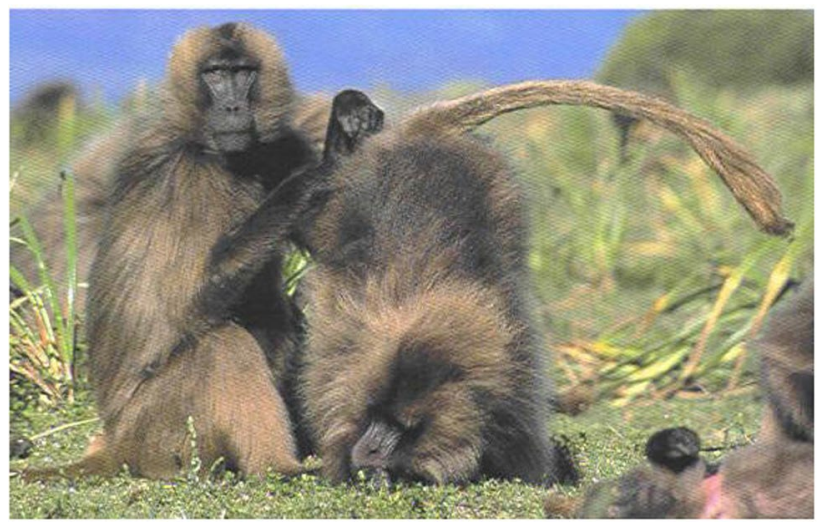

Fig. 3 Ethiopian gelada baboons (photo by Robin Dunbar) 
course of a three-month visit in 1979, with Professor Yukimaru Sugiyama acting as host, we managed to produce four papers, with Professor Kawai as the lead author on one of them. Inevitably, of course, they took a lot longer to actually appear in print (Kawai et al. 1983; Iwamoto and Dunbar 1983; Mori and Dunbar 1985; Ohsawa and Dunbar 1984). These papers pooled the data from our respective gelada studies in the Bole valley and the Sankaber and Gich areas of the Simen Mountains. It was, I think, the first serious attempt to undertake quantitative comparative studies of different populations of the same primate species. We attempted to understand how our populations differed, and why they did so, in terms of environmental differences between the study sites. Luckily, because the gelada are grass-eaters, their ecology is very simple, and this allowed us to make quantitative comparisons even with very few data.

These early papers had a very important consequence for me, because they made me realize that within-taxon quantitative comparisons of demography and foraging behavior could be very informative. One outcome was the series of time budget models that I later went on to develop for 10 primate genera and one ungulate genus (with models for two other primate genera contributed by other researchers): these models are better at predicting biogeographic distributions than conventional climate envelope models and provide much deeper insight into the environmental constraints that species are under because they focus on the physiological mechanisms that intervene between the environment and the animals' behavior. A second dimension to emerge out of these original Inuyama papers was a dozen comparative modeling papers on mating systems (in reality, the other half of the time budget models story). I would never have thought of approaching either of these sets of models as within-taxon analyses but for those seminal gelada papers that we put together in Inuyama. These papers are undoubtedly part of the legacy of Masao Kawai, and owe everything to his generosity and encouragement.

Of course, no visit would ever be complete without cultural experiences, and, during my visit, Professor Kawai had also generously made arrangements for me to visit Kyoto and the Arashiyama Japanese monkeys, Kyushu University (to meet with Iwamoto and Professor Yuiti Ono, with whom I shared an interest in Ethiopian antelope), and finally (courtesy of Akio Mori) a visit to the famous Koshima macaques (who, of course, treated me to a potato-washing demonstration) (Fig. 4). For me, it was a very stimulating and productive visit, not just to spend time hearing about Japanese primatology, but also to visit a lot of temples and other cultural sites. At the end of my visit, at a special dinner at his house, Professor Kawai presented me with a tea bowl made by a member of the famous Ichino family of potters from his hometown. Whenever I drink from it, as I do from time to

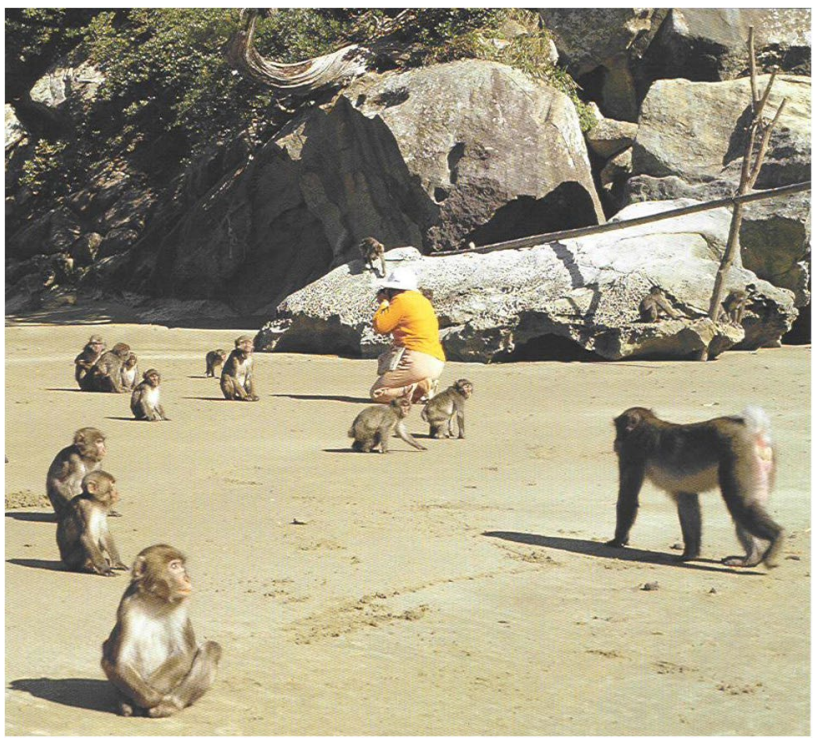

Fig. 4 Japanese monkeys in Koshima and Satsue Mito (photo taken in 1979 by Robin Dunbar)

time, I remember a scholar, a gentleman of the old school, a kindly man with a wry smile and a twinkle in his eye, one who selflessly encouraged us junior members of his gelada team. A memory to be cherished, and a scientific contribution to be honored.

\section{Professor Kawai, careful observer and careful interpreter}

\section{Dorothy Munkenbeck Fragaszy and Elisabetta Visalberghi}

We first encountered Professor Masao Kawai's writings as students in the 1970s when we were learning about ethology and comparative psychology, and beginning to study behavior in nonhuman primates from a biological perspective. We were interested at the time, as now, in the ways in which sociality is woven into the larger fabric of animals' lives. Thus, Professor Kawai's and colleagues' groundbreaking reports about the spread of novel behaviors among wild, provisioned Japanese macaques on Koshima were important to us. Fortunately, a few of them were translated into English. One of the most important of his works for shaping our thinking was his 1965 report in Primates summarizing many years of observations by him and his colleagues, particularly Syunzo Kawamura, of the demography of the group and of the monkeys' two novel feeding behaviors, washing sweet potatoes and sifting wheat. Professor Kawai carefully discussed the social context in which the novel behaviors appeared. Because the genealogy of many members of the group was known, Professor Kawai could determine how 
kinship, sex and age all impacted the timing in which monkeys acquired the behaviors. Further, he explained how the social context affecting acquisition of the behavior changed over time, as more individuals washed potatoes and sifted wheat. He stressed that provisioning the monkeys had dramatically changed their use of space, encouraging them to spend time on the sandy beach (where they were provisioned), and to enter the sea and to swim, which they had previously not been seen to do. He attributed their novel behaviors to the changes in their environment associated with provisioning. The eventual establishment of these novel behaviors as common elements of the repertoire, so that most young monkeys of the group learned them during their early years, he termed "pre-culture." He noted that sweet-potato washing had been observed among monkeys at other locations, but that in these groups it did not become established as a common behavior in the group. Why that should be the case was not addressed, but the implication we drew from this was that behavioral variability at the individual level sometimes, but not always, becomes variability across groups.

It is now nearly 50 years since we first read his paper. Rereading it while preparing this note, after decades of studying how monkeys move in the environment and interact with one another and their physical environment, we are struck by Professor Kawai's thorough descriptions of the monkeys' behavior, his wise interpretation of the observations, and his recognition of their significance for behavioral biology. His closing sentence rather succinctly frames a fundamental theme of behavioral biology from then to now: "Behavioral adaptability or plasticity in response to the change of environment will become important when we come to think of the evolution of behavior of the species" (Kawai 1965, p. 27).

We conducted an experimental study with captive monkeys of the novel behaviors of the wild, provisioned monkeys at Koshima described by Professor Kawai. Our study allowed us to consider the manner in which food washing was acquired, something that Professor Kawai could not address directly because observations of the monkeys at Koshima were intermittent. We studied tufted capuchin monkeys (now identified as Sapajus spp.; then identified as Cebus apella) and crab-eating macaques (Macaca fascicularis), closely related to Japanese macaques (Visalberghi and Fragaszy 1990). We showed that over the course of a few one-hour sessions, all individuals of both species spontaneously approached and touched water in a basin, capuchins with their hands and macaques by immersing themselves, and they put toys into and out of the water. All five capuchins and three of four macaques carried sandy fruits to the basin, released them into the water and retrieved them, or more actively dunked them back and forth in the water or rubbed them on the interior of the basin. We subsequently presented two larger groups of capuchin monkeys (combined $N=30$ ) with a basin of water and with clean fruit, sandy fruit, and grain mixed with sand. Some of these monkeys spontaneously brought sandy fruit (but not clean fruit) and sandy grain to the pan of water. With respect to how they began to wash fruit, crab-eating macaques were so enthusiastic about entering the basin of water, whatever they carried with them into the basin got wet (and clean!). Some capuchin monkeys learned that sandy food dropped into the water became better to eat, and gradually some of them adopted unambiguous washing behavior. We noted that individuals did not copy others; instead, they discovered the value of placing food into the water on their own.

Our understanding of how novel behaviors are acquired by multiple individuals in a group has come a long way since Professor Kawai noted the temporal pattern in which the monkeys in Koshima acquired sweet-potato washing and wheat washing. His seminal observations and writings served as a powerful source of ideas for the generations of researchers all around the world who have since tackled the important problems of how animals discover novel behaviors and how they learn in social settings with (but not necessarily directly from) other group members.

\section{Memories of a kind and helpful senior colleague}

\section{Steven Green}

My fond memories of Prof. Masao Kawai date back to mid1967 when my American colleagues and I arrived in Japan to begin research as part of a US-Japan cooperative science project. This was an exciting time in the emergence of significant primatological research in Japan. I, as a graduate student undertaking studies for my doctoral dissertation, was privileged to be warmly greeted by the senior colleagues based at Kyoto University and Osaka City University and to be joined by their graduate students for collaborative research at Arashiyama, Miyajima, and Koshima. Although Prof. Kawai was very much immersed at that time in the establishment of the Primate Research Institute at Kyoto University, he graciously accompanied us to Miyazaki Prefecture to introduce us to the macaques on Koshima Islet about which he had very recently published his groundbreaking paper on sweet-potato washing.

Although his spoken English skills were not as excellent as his writing, my Japanese language skills were less than rudimentary, so we managed to communicate in English through the assistance of the graduate students. When we were at this somewhat remote farming location, I wondered how it happened that scientists had been serendipitously in this area near the Toi peninsula and were therefore made aware of the 
macaque troops on Koshima. Prof. Kawai informed me of the work by Prof. Kinji Imanishi and his students on feral horses there and took us on a quick trip to view these horses. While there, Prof. Kawai informed us that it was the recognition of individual animals here that influenced Prof. Imanishi and his then students (Junichiro Itani and Syunzo Kawamura) to undertake the same animal-by-animal approach when they initiated studying the macaques on Koshima.

In addition to helping make the arrangements for us to stay at Mrs. Mito's inn across the water from Koshima, Prof. Kawai showed us how to identify individual monkeys, and he also demonstrated provisioning sweet potatoes so we could see first-hand the washing by Imo and her family. He kindly offered us one piece of critical advice as students beginning to study an animal society. He said we should spend as much time with them as possible, essentially living with them and becoming one with them. That resonated with me, in part because I am an animal lover and in part because it bridged the gap between the methodologies of objectivity I had been taught as a biologist and the revelations being uncovered about primate groups by anthropologists who took a much different approach. His advice, which permeated the rest of my professional career, became known as kyokan when he included it in his influential book Ecology of Japanese Monkeys (Kawai 1964) shortly afterwards.

I am therefore pleased to have the opportunity to share these memories of Prof. Masao Kawai as a kind man and an influential mentor as well as a pioneering scientist.

\section{In memory of Prof. Kawai}

\section{Hiroko Kudo-Hirotani}

Prof. Kawai is an important pioneer of Japanese primatology, and for years he was a highly respected instructor who provided valuable research guidance to graduate students belonging to the Primate Research Institute of Kyoto University.

Among his achievements, many field studies in Africa are special. In addition to conducting research with graduate students and other primatologists, he collaborated enthusiastically with experts in plant ecology and agriculture. Following early surveys in Tanzania and Ethiopia, large-scale surveys targeted primates in southern Cameroon, where a full-scale survey of mandrills and guenons (genus Cercopithecus) was conducted for more than five years.

The survey began with the creation of north, south, east, and west survey routes in the forest at regular intervals, and a hut was constructed so that researchers could stay on-site for several months. Based on the results of the survey in this area, several graduate students, including the author, wrote their dissertations.
Field surveys in tropical rain forests, where many bloodsucking insects and tropical diseases are widespread, were extremely difficult; our living conditions were harsh and the frequency of encounters with our target species remained low. Prof. Kawai encouraged us by showing us how to truly enjoy life in and around camp, and talking about various events in the rain forest. On one occasion, while living in a tent a few kilometers from the main camp, I was running out of time and feeling depressed due to the lack of encounters with mandrills, but my spirits were raised by the letter sent by Prof. Kawai. I still remember.

In the highlands of Ethiopia and in the rain forests of Cameroon, while observing various primates and listening to the students' stories about their observations and experiences, Prof. Kawai always aimed to establish a kind of mixed society of monkeys and humans, which I was happy to be associated with. He consistently tried to associate the diverse social structures of monkeys with the process of formation of human society. His approach was distinct from that of those studying ecology of apes. Now that more than 30 years have passed and much about the ecology of monkeys has been elucidated, can we say that perhaps the real value and validity of Prof. Kawai's approach is finally being recognized?

I pray for the souls of the pioneer teachers in the field of primatology, who showed us the value and the essence of monkey studies.

\section{Masao Kawai: the last of the grand pioneers of Japanese primatology}

\section{Michael A. Huffman}

I was deeply saddened to learn of Kawai sensei's passing on May 14, 2021. He was the last of the three grand pioneers of Japanese primatology, along with Junichiro Itani (1926-2001) and Syunzo Kawamura (1924-2003), who began their careers under Kinji Imanishi (1902-1992), the founder of primatology in Japan. These were the giants in our field in the early days, whose shoulders we stand upon today. I had not been able to see him for some time and was hoping to pay a visit as soon as the COVID pandemic was over and it was safe to meet. I wanted to reminisce about the past and thank him for the many ways he helped shape my career path in primatology and my staying here in Japan all these years.

I first met Kawai sensei on July 20, 1979, in his office on the fifth floor of Kyoto University's Primate Research Institute (PRI) in Inuyama. At the time, I was a 20-year-old undergraduate exchange student from Colorado studying at Kansai Gaidai in Osaka, taking courses in Japanese language, anthropology and other aspects of Japanese culture. 
At first, Japan was a serendipitous detour for this freshman in college, because for as long as I can remember I had wanted to go to Africa and study chimpanzees. But as my interests in Japan grew stronger, I was motivated to learn to read and write Japanese as well as speak it, so I combined this desire with my love of primates and started reading a copy of Ecology of Japanese Monkeys (1969), written in Japanese by Kawai sensei. On that fateful day in July, with his book in hand and an introduction from the professor at Gaidai who gave it to me, I went to meet the man who unknowingly was my first introduction to Japanese macaques and the world of Japanese primatology. We talked about the book and his pioneering fieldwork on sweet potato washing culture in Japanese macaques on Koshima and his early fieldwork in Africa. He was just beginning a new project on mandrills in Cameroon. After a cup of tea, he kindly signed the book, and then called Itani sensei in Kyoto on the phone to introduce me, while I waited.

A week later I was sitting in Itani sensei's office in the laboratory of Physical Anthropology on the main Kyoto campus, learning about his research on chimpanzees in Tanzania. At that moment, thanks to these two men, the path to Africa and my destiny in Japan became clear. Itani sensei introduced me to the monkeys of Arashiyama, and later arranged for me to begin studying chimpanzees in Mahale. As a graduate student studying under him in Kyoto from 1983, these two sites became key to beginning my career in primatology. Throughout the years, both of these kind men provided many opportunities as I integrated into the Japanese primatological community. Kawai sensei took an interest in the work I was doing on the stone-handling behavioral tradition of Japanese macaques and once invited me to co-appear on national TV to talk with him about culture in primates. With his trademark goatee and French beret, Kawai sensei always had a kind word when we met. His open and easygoing manner made him very approachable. Years later when colleagues and I were putting together an edited volume on 60 years of research at Arashiyama, he generously wrote a preface for it. Forty-two years from that fateful meeting in 1979, now just a few years from my own retirement from Kyoto University, my office here on the fifth floor of PRI is just a few doors down from where we first met. Every day I come to work, I am reminded of that fateful meeting, and am grateful.

These are the words I had wanted to share with Kawai sensei had we been able to meet again. For all these things I thank him from the bottom of my heart. He lived a long and productive life, remaining sharp of mind until the end, outliving his two classmates Itani and Kawamura by over 20 years. Kawai sensei leaves behind an indelible legacy in the field of primatology, and for that our entire discipline is grateful.

\section{Memorial essay for Dr. Kawai}

\section{Toshitaka Iwamoto}

I received a 2020 New Year's greeting card from Dr. Kawai with the message: "We miss Ethiopia, don't we?" I suspect that the expedition to study gelada baboons in the Semien Mountains National Park, Ethiopia, for 9 months (May 1973 to February 1974) was his proudest achievement (Kawai 1979a). After his long period of suffering from pulmonary tuberculosis as a youth, he miraculously recovered from the disease in Uganda, during his field study of colobus monkeys (Kawai 1998). Now cured and with 14 years of preparation behind him, he organized a team to study gelada baboons, comprising himself and three young scientists. Dr. Kawai added me to the team, while I was studying foraging ecology of Japanese macaques in Koshima, Miyazaki prefecture, where he had conducted studies on pre-cultural behaviors at the very beginning of his career in primatology (Kawai 1965).

In Ethiopia, this team faced many difficulties, such as getting permission to study in the era of Emperor Haile Selassie II, a very long journey to the field site by horse and mule caravan, extremely high altitude reaching almost $4000 \mathrm{~m}$ a.s.l., and freezing weather-around zero degrees Celsius. However, the vivid daily field experiences, observations of gelada baboons and their peculiar society and ecology, the overwhelming landscape of the Great Rift Valley, and a comfortable lodge-called Swiss House, built by Dr. B. Nievergelt (an ibex mammologist) with the help of C.W. Nicol (a naturalist and the park warden, Nicol 1972)—contributed to Dr. Kawai's mental and physical health being in the best condition. Such rich and unforgettable experiences in Semien spurred him to write those words above.

Fortunately, I continued to be a member of his team for more than 10 years, conducting collaborative work with him on gelada and hamadryas baboons in Ethiopia, mandrills in Cameroon and hamadryas baboons in Saudi Arabia. His most frequently uttered words in the field were: "I'm exhausted!" Of course, he had only one lung, the result of a surgical operation during his earlier disease.

Although many senior Japanese primatologists have unfortunately declined earlier in their careers, despite his extremely serious illness in his youth, Dr. Kawai survived until his mid-90s. I think that there are several reasons for this longevity, as follows:

First is his wife Ryoko's strict and careful management of him. She often joined our teams in the African field sites and cooked for him, and of course for us too.

Second is his tenacity to solve the question: "What is humankind?" The word "hominization" often appears in 
his books. Probably, he wanted to explain the process of hominization not only in terms of sociological and behavioral traits but also by the ecological constraints that primates confronted. I think that his way of thinking somewhat suggested inheritance of Dr. Kinji Imanishi's genes. He tried to build theories of hominization based not on aggression and antagonism but on segregation, avoiding competition and cooperation. He stressed the importance of peaceful manners and multilevel society (higher-level cooperation) in gelada baboons and in mixed-species groups of forestliving monkeys (Kawai 1998).

Third is his love of nature. I frequently witnessed how his spirits were raised when he went out in the fields. The fresh air and atmosphere as well as animals were surely the source of his healing. Throughout his expeditions, he repeatedly alternated between field sites, for example, forest (gorilla and colobus), grassland (gelada baboons), forest (mandrill) and grassland (hamadryas baboon). This order, of course, reflects the schedule for building and testing his theory, but it might reflect a sequence chosen to refresh his spirit continuously.

Fourth is his intention to write with Japanese words. His sentences in Japanese had a reputation for readability and simplicity. As a result, he published many books in Japanese. The Derivation of Human (the first and second volumes, in Japanese) are probably the most representative and laborious works, citing an enormous number of sources (Kawai 1992). However, it seems that he was not interested in translating his works into English, and therefore they are not well known to the wider primatological community. After retiring, he shifted to writing fantasy for children (Kusayama 2018), and eventually published several volumes of interpretation of profound fairy tales by Kenji Miyazawa (Kusayama 2011). It's easy to imagine that he was writing right up to his final day, which might be one way of countering age-related senility. Once, I asked him what his secret was to writing so many books. His answer was simple: "I do not sleep until I finish one manuscript page every night." Unfortunately, I was not a good student.

Dr. Kawai, please have a long and peaceful sleep without uttering: "I'm exhausted!"

\section{Play in nature}

\section{Tamaki Maruhashi}

The phrase is the motto of Professor Masao Kawai. He was born and grew up in Tamba-Sasayama, a small city, rich with nature. Later, when he became an honorary citizen, the city asked him to donate the calligraphy of his motto for it to be sculpted into a stone monument. The celebratory monument was set on the bank of Sasayama River, which he loved

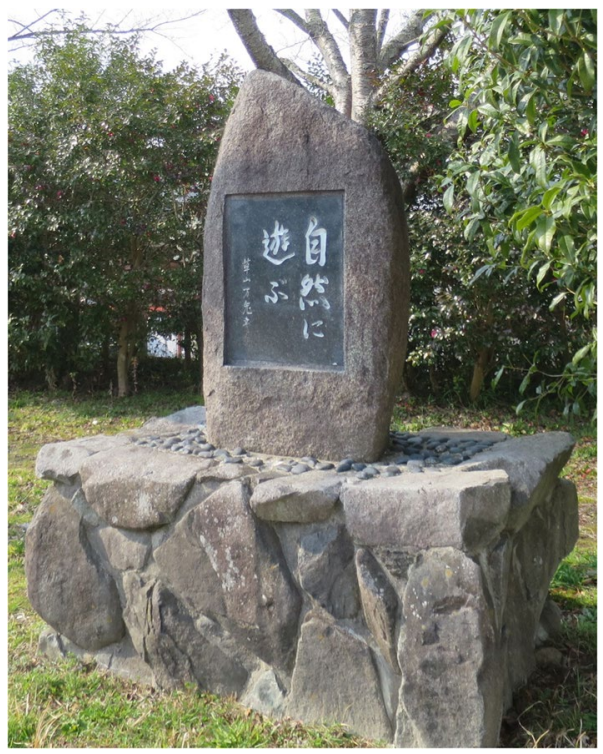

Fig. 5 The stone monument into which Professor Kawai's calligraphy of his motto "Play in Nature" is sculpted (photo by Tamaki Maruhashi)

(Fig. 5). It is a pleasant memory for me to have taken a souvenir photo with him and his wife in front of the monument. "Play in nature" was surely his strong belief throughout his entire life. He played in nature when he was a young boy, and continued to play in nature when he eventually became a scientist and a writer of children's literature as well.

In 1974, I became a graduate student of the Primate Research Institute (PRI) of Kyoto University. The graduate program in PRI started in 1972, so that I was a thirdyear student. I belonged to the Department of Sociology and Ecology, which was founded by Professor Kawai. He was my mentor for the 5-year program for my Ph.D. and very kind to me in both official and private aspects of life in PRI, Inuyama. At that time, his junior colleagues and students formed a team to study gelada baboons (Theropithecus gelada) in the highlands of Ethiopia. The team also made efforts to help the country establish a national park in the southern part of Omo Valley.

In the first 2 years of my Ph.D. program, for my master's degree I was free to choose a research topic. Under Professor Kawai's supervision, I targeted the Yakushima monkeys (Macaca fuscata yakui). I was very happy to succeed in habituating the wild monkeys without provisioning (Maruhashi 1980, 1981, 1982). In the following 3 years of the doctoral program, Professor Kawai gave me a new mission: pioneering work on hybrids of gelada and anubis baboons (Papio anubis) in Ethiopia. My teammates and I prepared a large amount of equipment for the field research, including two all-wheel-drive jeeps. We successfully shipped them to Djibouti, the port facing onto the 
Red Sea and the Gulf of Aden. Ethiopia was an empire for several hundred years, before falling into a chaotic period marked by civil wars. Professor Kawai made the decision to stop the fieldwork in Ethiopia, just one week before the scheduled departure. He wrote a book titled The forest provides the origin of primates (Kawai 1979b). The afterword of the book provides some details on those hard times and the difficult decision.

From a wide perspective, Professor Kawai shifted his attention from Ethiopia to Cameroon. He reorganized the research team to focus on mandrills (Mandrillus sphinx) and drills (Mandrillus leucophaeus) living in the tropical rain forests in Cameroon. At that time there were almost no field studies on the two species. They were supposed to have a multilevel society in which the units of one male with multiple females might merge into a larger group. He was very much interested in the evolutionary origins of human-like multilevel society.

For me, the first experience of overseas research was the travel with Professor Kawai. Let me introduce an episode. We were in Paris to change flights for Cameroon. At the time of boarding, I whispered to him, smiling.

Me: "Professor, do you have your passport and boarding pass?"

Professor: "Why not!" Then he paused and said, "Oh, my god, I have no passport!"

Me: "You may have left it at the immigration check."

Professor looked for it and said: "I found it!" He was relieved, and smiled.

The smile and his shining face reminded me of the face of a boy named Mato. Mato is the main character in his first children's book Forest school: Animals I have known in Tamba-Sasayama (Kawai 1975). Mato always smiled when he encountered something pleasant. We went to the forests in Cameroon and I was in charge of the study of drills in their natural habitat. However, I am sorry to say that the fieldwork on drills was very difficult due to the high hunting pressure.

Mato Kusayama is the pen name of Professor Kawai. In parallel with his effort as a scientist, he became a wellknown writer of children's literature. He published many books under this pen name. Between 2011 and 2018, when he reached 90 years of age, he published a series of four books on Kenji Miyazawa (1896-1933), a very popular poet and writer of children's literature in Japan. Kenji passed away at the young age of 37 years, so his reputation was formed only after his death. Professor Kawai kindly gave me the four books on Kenji, titled Understanding the soul of Kenji Miyazawa. Professor Kawai included a private card when he presented me with these books. The message on the card said: "Kenji wrote the books for children. There have been more than 300 books published since he died. However, all of them are for the adults, and no book has targeted children. I dared to write up this series of books on Kenji to talk to the young readers. During the challenge, I battled against the constraints of vocabulary and expression."

When I met Professor Kawai in 2016, he said: "My heart continues to beat. My brain continues to express various ideas." His wife, Ryoko-san, was sitting next to him and said: "My mission is to serve for his long life." She also mentioned: "I don't know what he writes, but he used to get up at 6 o'clock in the morning and always wrote something, till noon." His last book is titled DOEKURU expedition party (Kusayama 2018; Fig. 6). It is a fantasy about children and animals led by a man nicknamed "Wind" on a mission to find the Doedicurus in South America. Doedicurus is a huge, 4-m-long, armadillo-like mammal during the Pleistocene, and it went extinct about 11,000 years ago. The children's book is 732 pages. It was published in 2018, when he was 94 years old.

The last book contains the following message by the main character: "Books were the teacher of mine. I have another teacher: that is nature. Nature brings us a lot of wonder." I imagine, in his next life, Professor Kawai may continue to play in nature, talking and interacting with his beloved animals.

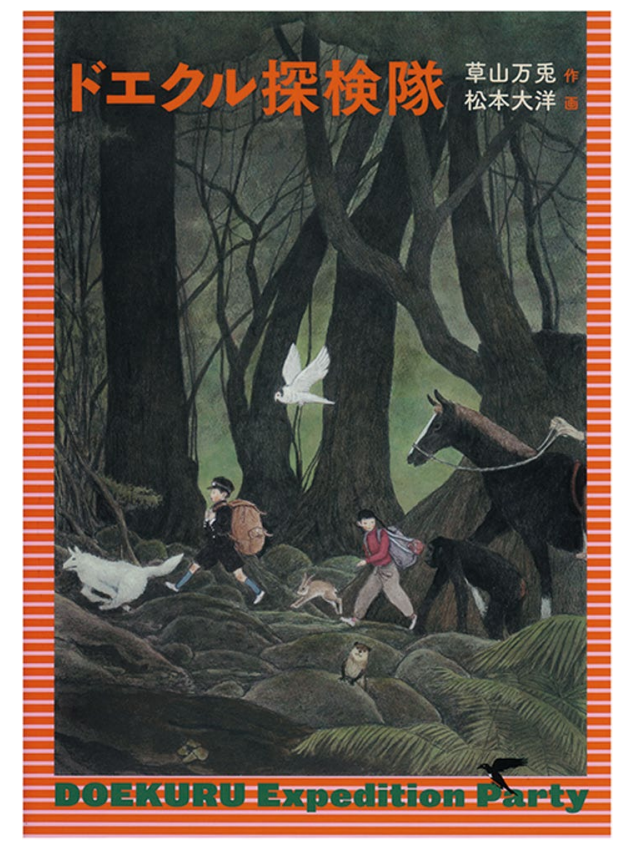

Fig. 6 The cover of DOEKURU Expedition Party: Text by Mato Kusayama, Illustrations by Taiyo Matsumoto, Fukuinkan Shoten Publishers, Inc 


\section{End of an era: Masao Kawai and the origins of modern primatology}

\section{William C. McGrew}

The passing of Masao Kawai signals the end of a longstanding connection to the origins of modern primatology in Japan. So far as I know, he was the last survivor of the original Primate Research Group assembled by Kinji Imanishi (Matsuzawa and McGrew 2008). The other six were Yoshio Furuya, Junichiro Itani, Syunzo Kawamura, Hiroki Mizuhara, Kisaburo Tokuda, and Munemi Yamada. All made contributions to our knowledge of Japanese macaques, and some went on to do trail-blazing primatological research on a global scale with a range of nonhuman primate species.

My attention was drawn to Japanese primatology long before I became a primatologist, via Imanishi's (1957) paper in Psychologia; also important to the English-speaking world was Kitahara-Frisch's seminal article in American Anthropologist (Frisch 1959). Abiding interest for me was reinforced by a personal subscription to Primates from Vol. 1 onwards. However, only after I became interested in the evolution of culture did I delve deeply into Kawai's work (e.g. 1965,1992), especially his Primates paper on pre-cultural behavior of Japanese macaques on Koshima.

The 1965 article showed prescience decades ahead of its time. Along with others, especially Kawamura (1959), it laid the groundwork for what later was to become a new subdiscipline: cultural primatology. It presented data on four behavioral patterns: sweet-potato washing, wheat washing (later called wheat placer mining), bathing, and "give-me-some." When read today, 55 years later, its ethological and ethnographic gems still ring true. A revisiting of the article by Hirata et al. (2001) yielded additional insights, reflecting continuing advances in primatology.

Not only were the subjects individually identified with given names, but their matrilines over years were clearly provided. The time courses of the diffusion of the new behavioral patterns were given in similar detail. The variables assessed, that is, age, sex, kinship, rank, remain core ones today. The key stages of acquisition and propagation remain important in current studies of cultural transmission. The qualitative descriptions (with exemplary photographs) and quantitative analyses remain fresh and useful, as Schofield et al. (2018) found in their re-examination of the data, which detected evidence of cumulative cultural change in Kawai's original data.

Even more important in many ways were Kawai's insights into the caveats and potential of such groundbreaking research. He sought to put the findings into wider perspective, giving comparisons with other populations of the monkeys for bathing but contrasting this with unique invention in their processing of potato and wheat. He noted cross-lineage differences in acquisition and propagation but was cautious about attributing this to any particular variable, anticipating debates that remain central to cultural primatology. Most importantly, he drew attention to the potentially confounding effects of provisioning, as a phenomenon that alters the environment and so influences behavior.

Kawai was a scientist of great foresight, from whom we still can learn much, decades later. When Scottish primatologists chose a name for their collaborative network, the Scottish Primate Research Group, we added only the adjective "Scottish" to Imanishi \& Co.'s precedent, by way of acknowledgement to our predecessors.

\section{The last of Kinji Imanishi's students}

\section{Akio Mori}

Masao Kawai was one of the founding members of Kyoto University Primate Research Institute (PRI), and he played a central role in field research of PRI. He worked together with others to establish PRI field stations for study and conservation of Japanese monkeys, and he especially worked to establish the Koshima field station for long-term studies. He also actively promoted overseas field studies by members of PRI. He served as the director of PRI and helped both field and laboratory researchers.

Kawai was one of the first students of Kinji Imanishi, the founder of Japanese primatology. This experience must have influenced his studies greatly. Imanishi promoted the comparative study of primate societies to understand the evolution of human society: the primatological approach. On the other hand, evolution of primate society can be studied from the perspective of human society: the anthropological approach. Imanishi often referred to findings from cultural and social anthropology in his writings. Kawai's findings about sweet-potato washing and sifting out wheat grains from sand in the Koshima group were interpreted as pre-cultural behavior. Kawai sustained Imanishi's view that evolution (changes) of primate social structure was realized through changes in social relationship between members of a group, rather than environmental (ecological) factors. This was clearly shown in his book. He tried to differentiate types of social structure in various Japanese monkey groups in terms of cultural differences (or characters of leader males), not mentioning ecological factors in any chapter of his book Nihonzaru no Seitai (Ecology of Japanese Monkeys, in Japanese), which was a "textbook" of Japanese monkeys and most widely read by students and intellectuals. He emphasized individual identification of monkeys and the role of 
artificial feeding in facilitating it. Individual identification by researchers, and by the monkeys themselves, is the basis for studying social relationships, which are the driving force of social evolution.

Imanishi sought out four characteristics of human society, and one of them was "establishment of regional community" (Imanishi 1965). He speculated about mechanisms of community in a gorilla society based on very early data. Kawai's studies conducted overseas were aimed at discovering types of social structures of communities and multilevel societies among primates. In Africa he studied gelada baboons and hybrid baboons, while other Japanese researchers focused on apes. He also tried to study mandrills and drills, but this proved very difficult; encounters with mandrill groups were rare, whereas those with mixed groups of guenons and mangabeys were frequent. He then obtained information about huge group sizes of hamadryas baboons in Saudi Arabia and thought of this as an opportunity to study a different type of multilevel society. Many of Kawai's studies were published by his students in English, but he published them in books and articles in Japanese. He preferred to express his ideas in Japanese, with nuances that are somewhat different from mainstream theories in the West. This kind of old practice among professors — writing in Japanese-seems impossible nowadays, with the requirements for ever-increasing numbers of papers published in international journals.

Kawai said that he was "flying by the one-lung engine plane," referring to his operation for tuberculosis. He walked and gathered data in fields while he was young, and visited his students in the field for short periods after he reached middle age. He experienced students' fieldwork and had on-site discussions with them. He was pleased to see his students wandering in the forest like "wild samurai warriors." His wife, Ryoko-san, sometimes accompanied him, saying that she was a "nurse" for his health problem. It is with pleasure that I remember them both sitting at a dining table together with us in a hut. Kawai invited non-primate ecologists, geneticists, researchers of medicinal plants, and many others to his field sites. He had wide-ranging knowledge, was interested in people, and welcomed them always.

\section{My mentor for life}

\section{Umeyo Mori}

I want to say: "Kawai-sensei, thank you for having guided me to the field study which had changed my life."

I lived on a mainland beach facing the Koshima Islet, which was $300 \mathrm{~m}$ offshore and inhabited by a Japanese monkey group. My grandfather ran an inn on the beach. Kinji Imanishi and two graduate school students, Itani and Kawamura, became customers. They walked all over the islet to catch glimpses of the monkey group and finally succeeded in provisioning monkeys. I was a primary school girl and got to know the students when high waves prevented them from crossing the strait. My mother, Satsue Mito, was interested in the monkeys, and observed them after they were provisioned at the sand beach of the islet. Masao Kawai came a few years after the first team, and stayed longer. My mother continued to visit the islet together with Kawai, and she took notes of monkeys while Kawai was absent. She saw a juvenile monkey washing a sweet potato in the seawater and reported that to Kawai, who then investigated how this new behavior was transmitted to other monkeys in the group. He reported the findings in a symposium in the USA, the first recognition of "pre-cultural behavior" among nonhuman primates.

I had no intention of becoming involved in the study of primates. I majored in mathematics at university, and obtained a job after graduation as a technical staff member at the Institute of Statistical Mathematics. Three years later, Kawai unexpectedly offered me a job in the newly established Kyoto University Primate Research Institute. I transferred between the Institutes. Kawai might have hoped that I would show the same determined observation efforts as my mother, or that my knowledge of statistics might help him someday. After a few years of work under Kawai, he gave me a theme to study: "the relationship between mothers and offspring in the Koshima group."

In 1973, 5 years after my transfer, I joined the team studying gelada baboons at Semien National Park. The team members were Kawai (director; communicative behavior), Ohsawa (population dynamics), Iwamoto (bio-economics), and me (social structure). We struggled to breathe in the thin air for around 20 days in the Ethiopian highlands, at an altitude of $3800 \mathrm{~m}$. We were on green grassland where it was easy to locate gelada groups. Each day we observed a band of 120 geladas which came up every morning having climbed the cliff face and went back down at dusk. They came up all together or in much smaller groups. One day, a huge group of around 350 geladas came along to where our band was. We expected great havoc, but the two (or more) bands moved around quietly as one group. The visiting group separated quietly after two days and moved back to their home area. We found three levels of gathering: one-male units, bands, and a huge association of bands. Kawai found "peaceful coexistence" of gelada bands without any noticeable dominance order, which moved Kawai profoundly. It seemed like one of the happiest times of his research life.

Kawai was seen always writing in his notebook, and he also took photographs of geladas. He gave us our photos taken at the field site, which helped us to recall the experience. He stressed the importance of relationships with 
people, and was a man who understood others and embraced them.

\section{Memories of field research with Prof. Kawai in Ethiopia}

\section{Hideyuki Ohsawa}

The invitation in 1973 to join a research expedition to study gelada baboons in Ethiopia was the start of the deep relationship between Professor Kawai and myself. It was during that expedition that Professor Kawai and I developed a strong working relationship and friendship, and he became my lifelong guide and mentor.

The deployment site of the 1973 expedition was in the highest mountains of Ethiopia, Ras Dashen. From the village at the base of these mountains, it was a whole-day trek to reach the field site, which was accessible only by a caravan of pack horses. Research equipment, including a radio-telemetry system, and food for several months were loaded onto the horses, just as things would have been in Livingstone's era.

Professor Kawai's health had always been fragile, and fieldwork at an altitude of 4000 m must have been very taxing for a 50-year-old with a single lung. Nevertheless, he walked around the highlands every day together with three young colleagues, Umeyo Mori, Toshitaka Iwamoto and myself, all in our twenties. In contrast, some young tourists who made the highland trek while we were there could only crawl at $4000 \mathrm{~m}$, and suffered from altitude sickness for the duration of their stay. Morning temperatures were freezing, and the ground was often covered with thick hail rather than snow. We lived in an austere hut in the national park and spent nights huddled in front of a fireplace, talking about what we had observed and our further study plans.

One of the debates between Professor Kawai and me concerned the characteristics of gelada social organization. My viewpoint, strongly influenced by population ecology, was that the gelada herd organization was due to fission and fusion among one-male groups as affected by their food resources. Later on, Dr. R. Dunbar and I named this herd organization an "ecological group," as opposed to the "social group," which was the one-male group. Professor Kawai, however, believed that the gelada herd occurred for social rather than ecological reasons. Although his thinking was very different from mine, he admitted that my idea was one he hadn't considered. This was but one example of his intellectual openness and generosity. The findings of the 1974 gelada research expedition were published in book form in 1979 (Kawai 1979a).
One important feature of Professor Kawai's academic activities in Japanese primatology must be noted. For a long time, Japanese primatology paid little attention to general ecology, such as feeding ecology, and its influence on behavior and social dynamics. This was due in part to the founder of Japanese primatology, Kinji Imanishi's, statement of his breaking from ecology. In the early stages of Japanese primatology, behavioral topics such as feeding ecology, which are not specific characteristics of primates alone, were somewhat neglected, because researchers were primarily focused on the study of characteristics unique to primates.

Of the direct followers of Kinji Imanishi, Professor Kawai alone worked with ecologists during the latter half of the 1960s to introduce ecological studies, such as feeding ecology and daily activity patterns, to Japanese primatology. In the 1970s he persuaded Toshitaka Iwamoto to undertake the first dedicated Japanese research into primate feeding ecology. Professor Kawai was also a pioneer of embedding technology in primate studies; he introduced radio telemetry to track the daily activity of primates.

In the early 1970 s some Japanese primatologists dismissed population ecology as little more than an arithmetic puzzle, or asserted that the quality and quantity of primate food is of little importance as long as monkeys survive. This did not bode well for me, having only just started studying primate population ecology. I was extremely fortunate that at around this time I was invited to conduct research with the support of Professor Kawai.

Now, in the twenty-first century, there are many Japanese primate ecologists whom I believe owe their place in Japanese primatology to the foresight of my mentor, colleague and friend, Professor Kawai.

\section{Professor Kawai: a pioneer and communicator}

\section{David S. Sprague}

Many readers of this journal can recall Kinji Imanishi's three students with whom he started research on Japanese monkeys, Syunzo Kawamura, Junichiro Itani, and, of course, Masao Kawai. Where Imanishi had inspired, the trio laid the initial foundations for primatology as an academic field. They carried out much of the original fieldwork on Japanese macaques. Then they went on to build the university departments, the degree programs, and the academic societies and journals that presented their work to the world, which laid out the path that so many of their students followed and allowed many non-Japanese students and colleagues to join them along the way. 
Perhaps more than anything else, the great legacy of the original trio were the field sites they established, and the support they gave to their students and colleagues who all contributed tremendously to what eventually grew into the global primatological ethos of see-for-yourself fieldwork. And Professor Kawai had been there from the beginning, when all of that was still in the future, still prospective ambitions in their heads, when their immediate goal was to put pen to paper in their field notes, recording for the first time the social interactions of Japanese macaques that they saw for themselves that have become so familiar to us now.

Even while building institutions, Professor Kawai and his colleagues continued to churn out important papers that defined the research paradigms within which many of us started to work when it became our turn to carry out our own fieldwork. I was always awed by the publication year of Professor Kawai's first papers describing the social structure of Japanese macaques, especially the ones on the rank and kinship structure of troops, 1958, in Primates Volume 1. My own personal acquaintance with him came decades later than these papers. I first met him at the Primate Research Institute (PRI), founded in 1967, in Inuyama during his term as the fourth Director, one of many offices he held at the PRI and the Primate Society of Japan during his long tenure there. I still recall vividly our first encounter, and how he was cheerful and welcoming in my courtesy call to the Director's office toward this utter novice undergraduate student claiming to be interested in primatology.

One of the engaging aspects of the original trio was that their research orientations were markedly different. Professor Kawai had always been pioneering an ecologically minded approach, and for many years his book titled Ecology of Japanese Monkeys $(1964,1969)$ was the first go-to book for students interested in the ecological research on monkeys. The field sites he trail-blazed from his base in the PRI were for species and places that targeted strategic theoretical issues, such as the gelada baboons of highland Ethiopia, and mandrills in Cameroon. Much of my association with Professor Kawai was through his students who launched the Yakushima study site where I carried out my own research. According to these students who worked with him, Professor Kawai apparently was more mindful in some of his field endeavors because of concerns about his health. Yet his style of living his life in a bit more deliberate but steady and persistent way has paid off. The patience and perseverance needed to start a new long-term field site, starting with the habituation of the primates, was taken for granted by his students. This indeed led to the successful habituation of the Yakushima monkeys without provisioning in just a few years after the initial attempts, all ready for me to gratefully start my project by the time I arrived there.
Another compelling aspect of Professor Kawai was that his books always connected with the general public. His books were widely appreciated by readers far and wide and brought in much needed public support for primatology and academic institutions, as well as generous funding from benefactors impressed with his work. In an era when the need for scientists and the public to understand one another is ever more acute, I keenly admired and will continue to aspire to his ability to communicate with the public.

\section{Sympathetic method: memory of late Professor Masao Kawai}

\section{Yukimaru Sugiyama}

When he was a child, the late Professor Masao Kawai suffered from juvenile tuberculosis, which resulted in his losing a lung. He became accustomed to calmly observing small animals and plants in the fields, rather than playing vigorous sports. He could neither climb up steep hills nor run in thick forests. In 1951, as a student at Kyoto University, he began his behavioral studies on a colony of rabbits which were enclosed in his parents' garden. This study drew him to ecology as well as sociology of animals.

Building upon the success of artificial feeding in 1952, he began to work on the Japanese macaques of Koshima, Kyushu, and joined the Primate Research Group under the leadership of the late Prof. Kinji Imanishi. The late Prof. Junichiro Itani was his colleague at this time, and both of them (Kawai and Itani) continued to be primatologists throughout their lives.

Kawai observed and described cultural behavior of macaques, so-called potato washing, and its impressive propagation process. This phenomenon was begun in 1953 by a juvenile female, learned by her mother and playmates, and then by other relatives. This transmission occurred without active teaching, but the behavior was not learned by adult males. It became a common custom of the troop, transmitted from one generation to the next. The story of the monkey culture expanded across the world. Kawai also analyzed the ranking system among individual monkeys in the troop, and how rank positions changed across situations. He named two different types of dominance rank: basic and dependent. These contributions to primatology in Japan during its early stages spread to other parts of the world, and remain important today.

In 1957 Kawai participated in the establishment of the Japan Monkey Centre (JMC), which he joined as a researcher. While on the staff of JMC he carried out a preliminary study of mountain gorillas in Uganda, Rwanda and Congo. In 1967 he moved to Kyoto University's Primate Research Institute. He organized a research team to work 
on hamadryas and gelada baboons at Semien, in the Ethiopian highlands. He went on to work on mandrills and other forest-dwelling primates at Campo, in southern Cameroon. At each of these research sites, at least one young colleague carried out long-term studies that produced important new data. Prof. Kawai published many books on primatology in Japanese, and emphasized the "sympathetic method" in which a researcher should share his or her feelings with the study subjects. His books on these topics attracted many Japanese readers.

Professor Kawai had a pen name: Mato Kusayama. Under this name he published many books on nature education and literature for youth, based on his own childhood experiences of plants and animals and the notion of sympatry. He emphasized in these books the importance of spending time in natural environments during childhood for maintaining sensibility throughout one's life. Once he obtained his research position, he worked so actively, it was as if he forgot about his missing lung.

\section{In memoriam: Masao Kawai and the foundations of cultural primatology}

\section{Andrew Whiten}

The cultural diffusion of sweet potato washing (SPW) and other novel behaviors discovered in Japanese macaques in the mid-twentieth century has become famous not only in textbooks and in the science of animal behavior generally, but far beyond this, amongst the public at large. It has been foundational in the subsequent flowering of cultural primatology, and discoveries about the broader reach of culture in animals' lives (Whiten 2021).

Masao Kawai played a unique and, in my view, a particularly significant role in attracting serious scientific attention to these early discoveries. The innovation of sweet-potato washing by the juvenile, Imo, in 1953 and its early spread to other monkeys on Koshima had been described by Syunzo Kawamura in a series of papers through the 1950s, but some were in Japanese, and even when appearing in English were largely verbal overviews (e.g. Kawamura 1959). Kawai went significantly beyond these and some other reports by his colleagues, notably Kinji Imanishi and Junichiro Itani (the latter on monkeys at Takasakiyama) to provide a landmark analysis that resonates much more with contemporary norms of scientific reporting (Kawai 1965). Kawai offered not only detailed descriptions of the cultural diffusion of a suite of four novel behaviors, but provided extensive supporting numerical data in the form of six tables and five graphs, as well as eight illustrative photographs.

Kawai's analysis prefigured multiple contemporary foci in the study of animal social learning and culture. Here I highlight four. First, in recent years, sophisticated statistical analyses such as "network-based diffusion analysis" have been developed that identify cultural transmission in wild populations because the diffusion spreads through social network connections (Hobaiter et al. 2014, for a primate example). Kawai made similar inferences through tracing the spread of SPW and other innovations such as wheat grain washing (WW), distinguishing a first period in which spread was from juveniles to their mothers, and a second in which such behaviors became group norms, routinely propagated from older to younger generations (continuing into the present century: Hirata et al. 2001).

Second, Schuppli et al. (2016) have highlighted and labeled as "peering" the close visual attention that young apes direct at novel actions performed by elders. These authors offer a series of empirical tests supporting the conjecture that this peering functions to acquire cultural information, and subsequently report that in orangutans this "peering" is evident in over 190 contexts, implying that in the words of the article's title, "we've only seen the tip of the iceberg" of culture in some animals' lives (Schuppli and van Schaik 2019). Fifty years earlier, Kawai had similarly noted that "being always with their mothers, babies stare at their mother's behavior while mothers are doing SPW behavior. Therefore, the process of propagation in this period is ... always from mother to child" (1965, p. 8).

Third, Kawai provided admirably fine-grained ethological observations of the details of the behavior of interest, including differences in styles of SPW, such as holding the item in one hand and brushing with the other, or rolling it in the water, or repeating dipping in the sea between bites. Fine-grained differences in chimpanzee termite fishing have recently been identified in different communities inferred to be variants whose transmission must rely on imitation, a contentious claim in primatology (Boesch et al. 2020). Half a century earlier, noting that the fine-grained variants of behavior often ran in families, Kawai suggested that "macaques are generally regarded as inferior in the ability of imitation ... but judging from the propagation of these two behaviors [SPW and WW], it may be acceptable that in a natural troop imitation through daily lives is made rather intensively" (1965, p. 24). Controversies about such inferences are still with us.

Fourth and finally, cumulative cultural evolution has long been described by many authors as unique to humans, but recent reports suggest that in elementary forms it may occur and even be not uncommon in some nonhuman cases (Whiten 2019). Half a century earlier, Kawai described cumulative aspects of the Koshima phenomena that included not only the progressive addition of other novel techniques (WW following SPW, for example), but also how cumulation occurred "within behavioral lineages" as it were, as SPW, initially done only in a freshwater stream, spread to the sea 


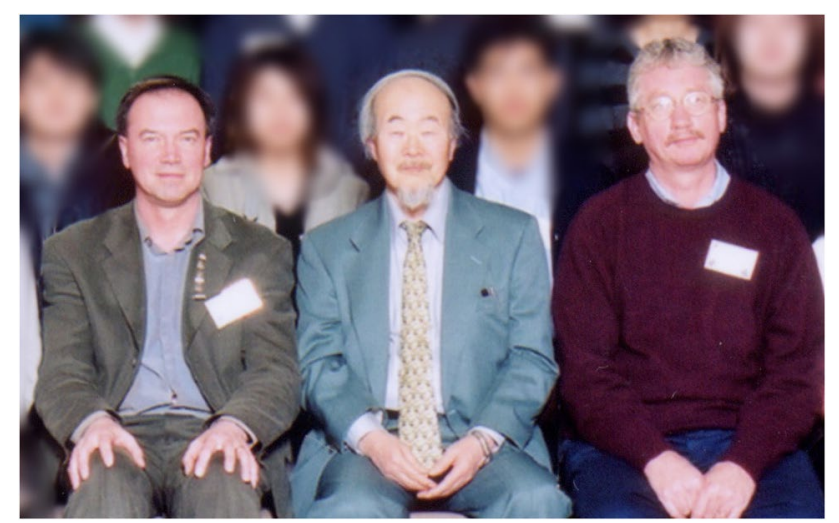

Fig. 7 Professors Masao Kawai (center), Andrew Whiten (left) and Frans B. M. de Waal (right). The photo is a part of a group photo taken on February 18, 2002, at the second International Symposium on Comparative Cognitive Science, held in Inuyama, Japan

and led to modifications such as repeated dipping to season the food, and as foraging in the sea led to new generations of youngsters who routinely swam there and dived off rocks into the sea, while the older generations still refused to get their feet wet. Schofield et al. (2018) offer a comprehensive analysis of the evidence for cumulative culture in the unfolding story of these monkeys' behaviors.

Although foundational to what now appears a "burgeoning reach" of culture in many animals' lives (Whiten 2021), Kawai's 1965 contribution remained at the time quite insular; of its 18 references, only two were non-Japanese. None referred to the reports of the diffusion of milk-bottle opening by tits in the UK over a decade earlier (Fisher and Hinde 1949), or the birdsong dialects described the year before (Marler and Tamura 1964; nor did these authors refer to Japanese monkeys). The latter authors described their findings as "cultural transmission," but Kawai remained shy of using the full "culture" word, conservatively referring only to "pre-culture." In other ways he was more amusingly adventurous. I had the privilege of meeting a lively Masao Kawai at a workshop in Japan in 2002 (Fig. 7), and I cannot help but imagine he had a twinkle in his eye when in the 1965 paper he suggested that SPW could be regarded as a kind of early "cooking," with a first physical phase of washing followed by a second, chemical phase of seasoning with seawater!

\section{Tribute to Prof. Kawai Masao}

\section{Juichi Yamagiwa}

Professor Kawai was the great pioneer of primatology. He is one of the first generation of Japanese primatologists, and was the last survivor. By the late 1940s, Imanishi Kinji and his students had started work in animal sociology, studying Japanese deer, horses and captive rabbits. Kawai studied rabbits and reported their dominance rank order for the first time. The results of their work were published in NihonDobutsuki, edited by Imanishi, because they called themselves "Setonians." Unlike most Western zoologists, who strictly avoided anthropomorphism, they identified each individual animal they observed and named it, as did Ernest Thompson Seton in his book Animal Heroes. They thought this method to be essential for illustrating social interactions among individual animals. In the early 1950s, they shifted their focus to Japanese macaques and started their field studies with provisioning macaques at Koshima and Takasakiyama. The main aim of their studies was to find evidence of social structure and culture unique to humans in macaques. Kawai conducted a prolonged field study and discovered pre-cultural behavior in the macaques in Koshima. In September 1953, a 1.5-year-old female macaque was observed to pick up a sand-covered potato, transport it to water, and wash it with water before eating it. This macaque also invented another food-preparation technique when she was 4 years old. She picked up wheat grains that had been scattered on the beach, transported them to seawater, and dropped them into the water. The sand sank, and she gathered and fed on the floating wheat grains. Kawai traced and analyzed the process of transmission of these newly acquired behaviors to other group members, and found that they were transmitted within the same generation through playmates, within kin groups, from young to old individuals, and some adult males did not acquire these behaviors. In contrast to human culture, which is most often transmitted from older to young individuals through social learning, pre-cultural behavior of Japanese macaques is transmitted from young to old, through individual learning probably with emulation. His paper describing these processes was published in Primates in 1965, and has been one of the most cited paper by Japanese primatologists.

Professor Kawai participated in the establishment of the Japan Monkey Centre in 1956 and supported its backbone as a researcher. In 1959, he visited the Virunga volcanoes in Uganda to conduct a survey on mountain gorillas. He reported on the non-territorial nature of gorilla groups in Primates in 1959, which preceded the investigations by George Schaller. He contributed to the creation of the primate zoo in the Japan Monkey Centre, characterized by its rich collection of primate species, with research and museum missions. He joined the newly established Primate Research Institute of Kyoto University as an associate professor in 1967, and started several expeditions in Africa. He conducted a survey on Cercopithecus monkeys using telemetry in Kibale Forest in Uganda, a survey on mandrills in southern Cameroon, and surveys on hamadryas and gelada baboons in the highlands of Ethiopia. He found that the 
extraordinarily large troops of gelada baboons consisted of many small one-male units that maintained peaceful relationships. He fostered many young researchers and students through these field surveys, and most of them subsequently got jobs as scientists.

He is known among Japanese primatologists for having extensive interactions with people from various disciplines, not only scholars but also artists, musicians, writers, and officials. Based on this wide range of human relationships, he served as the first president of the Primate Society of Japan, and after retirement from Kyoto University he returned to the Japan Monkey Centre to serve as director. He also served as director of the Museum of Human and Nature Activities in Hyogo Prefecture. He contributed to the conservation of Japanese macaques through their designation as a natural treasure by the National Agency of Cultural Affairs, and influenced policymaking for nature conservation by central and local governments. In Hyogo Prefecture, he conducted planning for the Wildlife Management Research Center, which was established in 2007 and is now well known for the highly successful management of Japanese wildlife including bears, boars, deer, and macaques, as well as alien species.

Prof. Kawai is also renowned as a writer of children's books. He wrote many books under the pseudonym "Kusayama Mato." Kusayama means grass mountain, a reference to the Satoyama area in his hometown. Mato refers to the tens of thousands of rabbits which he first studied in his research career. He won numerous awards and served as a judge for many awards. Three years before his death, at 94 years of age, he published a children's book entitled Doekuru expedition party, in which a boy and a girl are led by a professor (like Kawai himself) to the tropical rain forest of the Amazon and meet animals that were considered extinct in evolutionary history. He dreamt of field expeditions in unknown forests to promote harmonious relationships among wildlife.

Prof. Kawai has supervised me since I was an undergraduate student of Kyoto University. I studied Japanese macaques and gorillas by following his research experience. Thanks to his advice, I was able to survive in difficult situations in Africa. I worked with him when he was the director of the Japan Monkey Centre and the president of the Primate Society of Japan. He was a very thoughtful boss and good at dealing with people. His jokes always made people laugh and relaxed the atmosphere for those present.

Once I asked him why the first generation of Japanese primatologists started the new discipline against the trend in the Western scientists, who denied the existence of society and culture in nonhuman animals without language. Imanishi and his students including Kawai tried to overcome the high wall between human science and animal science by proving continuity of human and animal society. I was surprised at his answer. He said that "the painful memories of the Second World War led us to pose the question of what humans are and what society is. I thought we had to go back to the prehuman past to explore its essence." I strongly believe that we must carry on that feeling, to construct a new world without war and to promote harmonious relationships between humans and wildlife on this planet.

\section{A collective tribute to Professor Masao Kawai and his outstanding works}

\section{Masayuki Nakamichi}

On hearing about Professor Kawai's passing away peacefully of old age (he was 97 years old) on May 14, 2021, two things came to my mind, together with profound regret. The first was my few exciting encounters with Professor Kawai, and the second was the idea that, as Editorin-Chief of Primates, I would like to publish a collection of tributes to him from scholars in primatology to express our heartfelt thanks for him and his wonderful works.

Prof. Kawai observed individually identified Japanese monkeys in Koshima Islet and first clearly described the dominance hierarchy among the group members, using the concepts of dependent and basic ranks, in the late 1950s. His pioneering works were published in Volume 1 of Primates in 1958 (Kawai 1958a, b). He also discovered and described the emergence and propagation of sweetpotato washing behavior in the same group, and first wrote about the presence of "culture" in nonhuman animals. His paper on this topic, also published in Primates (Kawai 1965), has been widely cited not only by primatologists but also by many researchers in other fields. Moreover, Prof. Kawai organized research teams to study African monkeys including geladas, mandrills, and patas monkeys (Kawai et al. 1983). He introduced the use of telemetry for observing monkeys as early as the 1960s.

Prof. Kawai conducted these studies together with many colleagues, while supervising his students and leading the research teams including Japanese and non-Japanese scientists. Of course, his colleagues knew him personally. At the same time, I was sure that many scientists who did not know him personally nonetheless recognized the great significance of his works, which have greatly influenced generations of primatologists and their research. Therefore, with the support of two vice Editors-in-Chief, Jim Anderson and Satoshi Hirata, and Immediate-Past Editor-in-Chief, Tetsuro Matsuzawa, we asked not only Prof. Kawai's colleagues but also some scientists who did not know him personally to write short memorial messages to him. And they kindly accepted our request. Their attractive tributes include their own personal relationships with him, 
how much they were influenced by him or by his pioneering work, and so on. I would like to express my sincere thanks to all contributors for writing their heartfelt tributes in a very short period. Through the collection of these tributes, I hope that many readers will appreciate not only how much Prof. Kawai contributed to the development of primatology but also how much his understanding and warm personality charmed many scientists and encouraged them in their research activities.

Like most primatologists who came two or more decades after him, my first encounter with Prof. Kawai was through his book Nihonzaru no Seitai (Ecology of Japanese Monkeys, 1969). In April, 1976, when I became a second-year university student, I bought his book and finished reading it in only 3 days, as I had become so fascinated with the behaviors and lives of Japanese monkeys, and the scientific processes of unveiling their unknown behaviors. I may say that Kawai's book, together with another book, Takasakiyama no Saru (Japanese monkeys in Mt. Takasaki) by Junichiro Itani (1954), invited me to primatology. In fact, 2 years later I started observing Japanese monkeys. Since then, I have observed Japanese monkeys and some other primate species, using individual identification in the same way as Prof. Kawai. I read Nihonzaru no Seitai once again and rediscovered his basic and invaluable findings on Japanese monkeys, along with references to human behaviors and society, although the book was written only around 10 years after the very first observations on Japanese monkeys. His book includes almost all of the important behavioral topics about Japanese monkeys: dependent and basic ranks, dominance relations, kinship, leader-follower relations, grooming, sexual behaviors and incest, personality, group differences in behaviors, propagation of newly acquired behaviors and culture, communication, and so on. Although some descriptions should be rewritten to incorporate new findings, I'm sure that, unlike with many common textbooks, readers can have fun while learning about the monkeys' behaviors and their society. Moreover, like me, as they read this book, primatologists may still come up with new ideas and perspectives for further studies.

With one exception, I had never had any real opportunities to talk with Prof. Kawai, as I learned primatology in a different university, and was hesitant to approach and talk with the outstanding primatologist and author of Nihonzaru no Seitai. My long-awaited chance came almost 20 years after reading the book, and a few weeks after I'd received a manuscript acceptance letter from Primates with the signature of Editor-in-Chief Kawai. In that paper I first reported that the aged and declining alpha male of the group was partly dependent on the alpha female for maintaining his dominance over the second-ranking, younger and healthier male, and I referred to Prof. Kawai's paper (Nakamichi et al. 1995). At a party after a scientific meeting, I decided to approach him just to express my thanks for his comments on the manuscript and its acceptance for publication in Primates. Happily, he welcomed me and began talking with me. His warm and caring attitude emboldened me enough to continue talking with him for more than 10 minutes without feeling overawed. I do not remember most of the subjects about which we talked, but I remember that he pointed out the importance of describing interactions among monkeys in detail and paying attention to infrequently observed events such as the one which I'd reported. He encouraged me to continue observing monkeys in the same manner.

Prof. Kawai was the Editor-in-Chief of Primates for 15 years, from 1981 to 1995 , during which period he continued to contribute to the development of primatology through the journal. I am now in the same position as the late Prof. Kawai. Like him, I would like to continue efforts to make the journal better and stronger-one of the leading outlets in primatology — and I am grateful to him for helping to set me on that road.

\section{References}

Boesch C et al (2020) Chimpanzee ethnography reveals unexpected cultural diversity. Nat Hum Behav 4:910-916. https://doi.org/10. 1038/s41562-020-0890-1

de Waal FBM (2003) Silent invasion: Imanishi's primatology and cultural bias in science. Anim Cogn 6:293-299. https://doi.org/10. 1007/s10071-003-0197-4

Fisher J, Hinde RA (1949) The opening of milk bottles by birds. $\mathrm{Br}$ Birds 42:347-357

Frisch JE (1959) Research on primate behavior in Japan. Am Anthropol 61:584-596. https://doi.org/10.1525/aa.1959.61.4.02a00040

Grueter CC, Chapais B, Zinner D (2012) Evolution of multilevel social systems in nonhuman primates and humans. Int J Primatol 33:1002-1037. https://doi.org/10.1007/s10764-012-9618-z

Hirata S, Watanabe K, Kawai M (2001) "Sweet-potato washing" revisited. In: Matsuzawa T (ed) Primate origins of human cognition and behavior. Springer, Tokyo, pp 487-508. https://doi.org/10. 1371/journal.pbio.1001960

Hobaiter C, Poiset T, Zuberbühler K, Hoppitt W, Gruber T (2014) Social network analysis shows direct evidence for social transmission of tool use in wild chimpanzees. PLoS Biol 12:e101960. https://doi.org/10.1371/journal.pbio.1001960

Imanishi K (1957) Social behavior in Japanese monkeys, Macaca fuscata. Psychologia 1:47-54. https://doi.org/10.2117/psysoc.1957.47

Imanishi K (1965) The origin of human family-a primatological view. In Kawamura S, Itani J (eds), Monkeys and apes-sociological studies, contributions in honor of Dr. Kinji Imanishi on the occasion of his sixtieth birthday, Chuou Kouronsha, pp. 3-47, (in Japanese), (originally published in Japanese). J Ethnol Study 25:119-138. https://doi.org/10.14890/minkennewseries.25.3_119

Imanishi K, Altmann SA (eds) (1965) Japanese monkeys: a collection of translations. SA Altmann, Chicago

Isbell LA, Pruetz JD, Lewis M, Young TP (1998) Locomotor activity differences between sympatric patas monkeys (Erythrocebus patas) and vervet monkeys (Cercopithecus aethiops): implications for the evolution of long hindlimb length in Homo. Am J Phys 
Anthropol 105:199-207. https://doi.org/10.1002/(SICI)10968644(199802)105:2\%3c199::AID-AJPA7\%3e3.0.CO;2-Q

Itani J (1954) Takasakiyama no Saru (Japanese monkeys in Mt. Takasaki). Kobunsha, Tokyo

Iwamoto T, Dunbar R (1983) Thermoregulation, habitat quality and the behavioural ecology of gelada baboons. J Anim Ecol 52:357-366. https://doi.org/10.2307/4559

Kawai M (1958a) On the rank system in a natural group of Japanese monkey (I). Primates 1:111-130. https://doi.org/10.1007/BF01813699

Kawai M (1958b) On the rank system in a natural group of Japanese monkey (II). Primates 1:131-148. https://doi.org/10.1007/BF01813700

Kawai M (1964) Nihonzaru no Seitai (Ecology of Japanese monkeys). Kawade Shobo Shinsha, Tokyo (In Japanese)

Kawai M (1965) Newly-acquired pre-cultural behavior of the natural troop of Japanese monkeys on Koshima islet. Primates 6:1-30. https://doi.org/10.1007/BF01794457

Kawai M (1969) Nihonzaru no Seitai: revised edition (Ecology of Japanese monkeys: revised edition). Kawade Shobo Shinsha, Tokyo (In Japanese)

Kawai M (1975) Shounen-Doubutsu-Shi (Forest school: animals I have known in Tamba-Sasayama). Fukuinkan Shoten Publishers, Tokyo (In Japanese)

Kawai M (1979a) Ecological and sociological studies of gelada baboons. Contributions to Primatology, Vol.16. Kodansha, Tokyo \& S. Karger, Basel

Kawai M (1979b) Shinrin ga Saru wo Unda: Genzai no Shizenshi (The forest provides the origin of primates). Heibonsha, Tokyo (In Japanese)

Kawai M (1985) Birth of the primate society of Japan. Primate Res 1:1-3. https://doi.org/10.2354/psj.1.1 (In Japanese)

Kawai M (1992) Ningen no Yurai, (Derivation of Human: The first and second volume). Shougakukan, Tokyo (In Japanese)

Kawai M (1998) Saru kara Hito heno Monogatari (Stories from monkey to human: Collection of Books by Masao Kawai, No. 7). Shogakukan, Tokyo (In Japanese)

Kawai M, Ohsawa H, Mori U, Dunbar R (1983) Social organization of gelada baboons: social units and definitions. Primates 24:13-24. https://doi.org/10.1007/BF02381450

Kawai M, Watanabe K, Mori A (1992) Pre-cultural behaviors observed in free-ranging Japanese monkeys on Koshima islet over the past 25 years. Primate Rep 32:143-153

Kawamura S (1959) The process of sub-culture propagation among Japanese macaques. Primates 2:43-60. https://doi.org/10.1007/ BF01666110

Kusayama M (2011) Miyazawa Kenji no Kokoro wo Yomu (Understanding the soul of Kenji Miyazawa: The first to fourth volume). Douwaya, Tokyo (In Japanese)

Kusayama M (2018) Doekuru Tankentai (DOEKURU expedition party). Fukuinkan Shoten Publishers, Tokyo (In Japanese)

Marler P, Tamura M (1964) Song "dialects" in three populations of white-crowned sparrows. Science 146:1483-1486. https://doi.org/ 10.1126/science.146.3650.1483

Maruhashi T (1980) Feeding behavior and diet of the Japanese monkey (Macaca fuscata yakui) on Yakushima Island, Japan. Primates 21:141-160. https://doi.org/10.1007/BF02374030

Maruhashi T (1981) Activity patterns of a troop of Japanese monkeys (Macaca fuscata yakui) on Yakushima Island, Japan. Primates 22:1-14. https://doi.org/10.1007/BF02382552

Maruhashi T (1982) An ecological study of troop fissions of Japanese monkeys (Macaca fuscata yakui) on Yakushima Island, Japan. Primates 23:317-337. https://doi.org/10.1007/BF02381317

Matsuzawa T, McGrew WC (2008) Kinji Imanishi: pioneer of primatology. Curr Biol. https://doi.org/10.1016/j.cub.2008.05.040

Matsuzawa T, Yamagiwa J (2018) Primatology: the beginning. Primates 59:313-326. https://doi.org/10.1007/s10329-018-0672-9
Mori U, Dunbar R (1985) Changes in reproductive condition of female gelada baboons following takeover of one male units. Z Tierpsychol 67:215-224. https://doi.org/10.1111/j.1439-0310.1985.tb01390.x

Nakagawa N (1989) Activity budget and diet of patas monkeys in KalaMaloue National Parkd, Cameroon: a preliminary report. Primates 30:27-34. https://doi.org/10.1007/BF02381208

Nakagawa N (1998) Ecological determinants of the behavior and social structure of Japanese monkeys: a synthesis. Primates 39:375-383. https://doi.org/10.1007/BF02573085

Nakagawa N (1999) Differential habitat utilization by patas monkeys (Erythrocebus patas) and tantalus monkeys (Cercopithecus aethiops tantalus) living sympatrically in northern Cameroon. Am J Primatol 49:243-264. https://doi.org/10.1002/(SICI)10982345(199911)49:3\%3c243::AID-AJP3\%3e3.0.CO;2-4

Nakagawa N (2000a) Foraging energetics in patas monkeys (Erythrocebus patas) and tantalus monkeys (Cercopithecus aethiops tantalus): implications for reproductive seasonality. Am J Primatol 52:169-185. https://doi.org/10.1002/1098-2345(200012)52:4\% 3c169::AID-AJP2\%3e3.0.CO;2-B

Nakagawa N (2000b) Seasonal, sex, and interspecific differences in activity time budgets and diets of patas monkeys (Erythrocebus patas) and tantalus monkeys (Cercopithecus aethiops tantalus), living sympatrically in Northern Cameroon. Primates 41:161174. https://doi.org/10.1007/BF02557797

Nakagawa N (2003) Difference in food selection between patas monkeys (Erythrocehus patas) and tantalus monkeys (Cercopithecus aethiops tantalus) in Kala Maloue National Park, Cameroon, in relation to nutrient content. Primates 44:3-11. https://doi.org/10. 1007/s10329-002-0001-0

Nakagawa N (2008) Despotic wild patas monkeys (Erythrocebus patas) in Kala Maloue, Cameroon. Am J Primatol 70:238-246. https:// doi.org/10.1002/ajp.20481

Nakagawa N (2010) Intraspecific differences in social structure of the Japanese macaques: a revival of lost legacy by updated knowledge and perspective. In: Nakagawa N, Nakamichi M, Sugiura H (eds) of the Japanese macaques. Springer, Tokyo, pp 271-290

Nakagawa N (2015) The Origin and evolution of humans from a viewpoint of studies on monkeys. Puneuma-sha, Tokyo (In Japanese)

Nakagawa N, Iwamoto T, Yokota N, Soumah AG (1996) Interregional and inter-seasonal variations of food quality in Japanese macaques: constraints of digestive volume and feeding time. In: Fa JE, Lindburg DG (eds) Evolution and ecology of macaque societies. Cambridge University Press, Cambridge, pp 207-234

Nakagawa N, Matsubara M, Shimooka Y, Nishikawa M (2015) Embracing in a wild group of Yakushima macaques (Macaca fuscata yakui) as an example of social customs. Curr Anthropol 56:104-120. https://doi.org/10.1086/679448

Nakamichi M, Kojima Y, Itoigawa N, Imakawa S, Machida S (1995) Interactions among adult males and females before and after the death of the alpha male in a free-ranging troop of Japanese macaques. Primates 36:385-396. https://doi.org/10.1007/BF02382861

Nicol CW (1972) From the roof of Africa. Knopf, New York

Ohsawa H, Dunbar R (1984) Variations in the demographic structure and dynamics of gelada baboon populations. Behav Ecol Sociobiol 15:231-240. https://doi.org/10.1007/BF00292980

Schofield DP, McGrew WC, Takahashi A, Hirata S (2018) Cumulative culture in non-humans: overlooked findings from Japanese monkeys? Primates 59:113-122. https://doi.org/10.1007/s10329-017-0642-7

Schuppli C, van Schaik CP (2019) Animal cultures: how we've only seen the tip of the iceberg. Evol Hum Sci 1:e2. https://doi.org/10. 1017/ehs.2019.1

Schuppli C, Meulman EJM, Forss SIM, Aprilinayati F, van Noordwijk MA, van Schaik CP (2016) Observational learning and socially induced practice of routine skills in immature orangutans. Anim Behav 119:87-98. https://doi.org/10.1016/j.anbehav.2016.06.014 
Visalberghi E, Fragaszy DM (1990) Food-washing behaviour in tufted capuchin monkeys and crabeating macaques. Anim Behav 40:829-836. https://doi.org/10.1016/S0003-3472(05)80983-2

Whiten A (2019) Cultural evolution in animals. Ann Rev Ecol Evol Syst 50:27-48. https://doi.org/10.1146/annurev-ecolsys-110218-025040

Whiten A (2021) The burgeoning reach of animal culture. Science 372:abe6514. https://doi.org/10.1126/science.abe6514
Whiten A, Goodall J, McGrew WC, Nishida T, Reynolds V, Sugiyama Y, Tutin CEG, Wrangham RW, Boesch C (1999) Cultures in chimpanzees. Nature 399:682-685. https://doi.org/10.1038/21415

Publisher's Note Springer Nature remains neutral with regard to jurisdictional claims in published maps and institutional affiliations. 